\title{
Kendiliğinden Yerleşen Harçlarda Portland Çimentosu, Silis Dumanı, Uçucu Kül Kombinezonlarının Basınçlı Su Geçirgenliğine Etkisi
}

\author{
Paki TURĞUT ${ }^{1 *}$, Kazım TÜRK², Nuray KARADAŞ ${ }^{3}$ \\ ${ }^{1}$ İnşaat Mühendisliği Bölümü, Mühendislik Fakültesi, İnönü Üniversitesi, Malatya, Türkiye \\ 2 İnşaat Mühendisliği Bölümü, Mühendislik Fakültesi, İnönü Üniversitesi, Malatya, Türkiye \\ ${ }^{3} \mathrm{Su}$ ve Kanalizasyon İdaresi Genel Müdürlüğü, Şanlıurfa Büyükşehir Belediyesi, Şanlıurfa, Türkiye \\ *11 pakiturgut@inonu.edu.tr, 22 kazim.turk@inonu.edu.tr, nuraycekilmez63@gmail.com
}

Öz: Su depolarında, baraj yapılarında, bazı endüstriyel binaların yapımında ve onarımında kullanılan beton ve harçların, basınçlı su geçirgenliği değeri dayanıklılık bakımından büyük öneme sahiptir. Bu çalışmada, Portland çimentosu, silis dumanı ve uçucu kül içeren ikili ve üçlü kendiliğinden yerleşen harçlarda ve bunların kombinezonlarından oluşan numunelerde basınçlı su geçirgenliği araştırılmıştır. Bu örneklerde basınçlı su işleme derinliği belirlenmiştir. Portland çimentosu ve \%10 silis dumanı içeren ikili numunede, Portland çimentosu, \%10 silis dumanı ve \%35 uçucu kül içeren üçlü numunede basınçlı su geçirgenliği değerleri azaltılmıştır.

Anahtar kelimeler: Kendiliğinden yerleşen harç, silis dumanı, uçucu kül, basınçlı su geçirgenliği.

\section{Effect of Portland Cement, Silica Fume, Fly Ash Combinations On Pressurized Water Permeability of Self-Compacting Mortars}

\begin{abstract}
The water permeability has great importance with respect to durability for concrete structures subjected to pressure and mortars used in construction and repair of water tanks, dam structures, and some industrial buildings. In this work, the water permeability under pressure was investigated in binary and ternary self-compacting mortars with Portland cement, silica fume and fly ash, and at their combinations. Water penetration depths were determined in these samples. The water penetration depths were decreased in the binary sample containing Portland cement and $10 \%$ silica fume, and the ternary sample containing Portland cement, $10 \%$ silica fume and 35\% fly ash.
\end{abstract}

Key words: Self-compacted mortar, silica fume, fly ash, pressurized water penetration.

\section{Giriş}

Bir yapının dayanıklılı̆̆ı, söz konusu yapının hizmet ömrüyle aynı anlama gelmekte ve çevresel faktörlerden etkilenmektedir. Bir yapının herhangi bir çevre koşulundaki dayanıklılı̆̆ı, bir başka çevre koşulundaki dayanıklılığını ifade etmemektedir. Bağlayıcı olarak Portland çimentosu kullanılmış betonun dayanıklılığı, bu betonun ufalanmaya, kimyasal saldırıya, aşınmaya ve diğer bozulma etkilerine karşı direnci olarak tanımlanmaktadır [1]. Bir başka deyişle, bulunduğu çevrenin zararlı etkilerine maruz kaldığında, gerçek yapısını ve kalitesini hizmet süresince kaybetmeyen beton olarak isimlendirilmektedir. Gerçekte, yapılarda kullanılan malzemelerin hiçbirisi kalıtsal olarak dayanıklı değildir. Zararlı çevrenin etkisiyle mikro-yapıları ve bazı özellikleri zamanla değişebilmektedir. Kullanım koşulları göz önüne alınarak tasarlanmış bir malzemenin tahribata uğraması, bu malzemenin kullanıldığı yapıda güvensizlik ve masraf oluşturuyorsa, o malzemenin hizmet ömrünü tamamladığı kabul edilmektedir [2]. Bu nedenle, yapı malzemelerinin mekanik özellikleri ve üretim maliyetlerinin yanında, dayanıklılığı da mutlaka dikkate alınmalıdır. Yapılarda kullanılan malzemelerde meydana gelen tahribatlardan dolayı yapılacak bir onarım, başlangıçta hesaplanan toplam yapı maliyetini etkilemektedir.

Yapı malzemelerinin içinde bulunduğu zararlı çevre koşulları değişkenlik gösterebilir. Bu zararlı çevre koşullarından birisi, yapı malzemesinin temas ettiği sudur. Yaşam için zorunlu olan su, aynı zamanda birçok doğal malzemenin bozulmasında da önemli rol oynamaktadır. Betonun dayanıklılığında da birçok problemler ortaya çıkarmaktadır. Boşluklu katılara etki eden su, hem fiziksel hem de kimyasal bozulmanın birçok aşamasında yer almaktadır. Boşluklu katılar içerisinde suyun dolaşımıyla oluşan fiziko-kimyasal olaylar,

\footnotetext{
* Sorumlu yazar: paki.turgut@inonu.edu.tr. Yazarların ORCID Numaras1: ${ }^{1} 0000-0002-3711-4605,{ }^{2} 0000-0002-9488-1587,{ }^{3} 0000-0003-$ 3164-0724
} 
katılarda su geçirgenliğinin artmasıyla meydana gelmektedir. Betondaki kimyasal bozulma, kimyasal etkiye maruz kalan betonun ya yüzeyiyle sınırlı kalmakta ya da betonun iç kısımlarında oluşmaktadır. Yapı malzemesindeki tahribatın hızı, betonu oluşturan bileşenlerin özelliklerinin yanında su içerisindeki iyonların yoğunluğuna ve tipine de bağlı olmaktadır.

Deniz, yeraltı, nehir, göl, buz ve su buharı yeryüzünde bulunan en bol sulardır. Suyun molekül boyutu oldukça küçük olduğundan, küçük boşluklara ve çatlaklara kolayca girebilmektedir. Suyun çözme özelliği diğer sıvılardan oldukça yüksektir. Bazı durumlarda suyun içerisinde değişik iyonlar ve gazların bulunması, katılaşmış çimento hamurunun kimyasal çözünmesine neden olmaktadır. Mehta ve Gerwick [3], betondaki kimyasal bozulmayı üç gruba ayırmıştır; Birincisi, çimento hamuru bileşenlerinin yumuşak suyla hidrolizidir. İkincisi, zararlı kimyasal sıvılar ile çimento hamuru arasında katyon değişimidir. Sonuncusu ise, betonda genleşmeye sebep olan sülfat saldırısı, alkali-agrega reaksiyonu ve donatının paslanmasıdır. Fiziksel veya kimyasal tahribatlardan herhangi birinin başlaması, bunlardan herhangi birisinin işini daha da kolaylaştırmaktadır. Örneğin, betonun yüzeyine yakın kısmının fiziksel olarak hasar görmesi, eğer söz konusu beton kimyasal olarak zararlı bir ortamdaysa kimyasal tahribatı hızlandırmaktadır. Böylece, kimyasal etkiden kaynaklanan bozulma da, fiziksel bozulma ortaya çıkarmaktadır. Örneğin, sertleşmiş çimento hamurundaki bileşenlerin yumuşak suyla veya asidik sıvılarla dışarıya salınımı, betonun içindeki boşluk miktarını artırmaktadır. Böylece, beton aşınma etkilerine de dayanıksız olmaktadır.

Betonun dayanıklılığını etkileyen önemli faktörlerin en başında, sıvıların sertleşmiş çimento hamurun içerisinden geçirgenliği gelmektedir. Düşük su geçirgenliğine sahip betonların, yüksek dayanım ve dayanıklılık sağladığı bilinmektedir. Geçirgenliği düşük olan betonların kimyasal saldırılara karşı direnci daha yüksek olmaktadır. Betonun içerisine basınç etkisiyle ya da normal veya kılcal yolla su geçtiğinde, klor iyonları içeren çözünebilir tuzlar da beton içerisine taşınmaktadır. Bu tuzlar donatının korozyonuna ve hidratasyon ürünlerinin değişerek bozulmasına sebep olmaktadır. Dolayısıyla, genellikle düşük sıvı geçirgenliğine sahip olan betonların dayanıklılığı yüksek olmaktadır [4]. Yukarıda belirtilen nedenlerden dolayı, betonun basınç etkisindeki su geçirgenliğinin incelenmesi ve gerekli önlemlerin betonun tasarım aşamasında dikkate alınması önem kazanmaktadır. Hidratasyon olayının tamamen gerçekleştiği Portland çimentosu hamurunda oluşan kalsiyum silikat hidrat $(\mathrm{CSH})$, kalsiyum hidroksit $(\mathrm{CH})$ ve kalsiyum alüminat-silikat hidrat $(\mathrm{CASH})$ çözünmez hidratasyon ürünleri, bu ürünlerin içerisindeki veya etrafındaki boşluk sıvısının pH değerinin yüksek olması durumunda denge halindedir. Boşluk sıvısı içerisindeki $\mathrm{Na}^{+}, \mathrm{K}^{+}$ve $\mathrm{OH}^{-}$iyonlarının miktarına bağlı olan sertleşmiş Portland çimentosu hamurunun $\mathrm{pH}$ değerleri 12.5 ile 13.5 arasında değişmektedir. Sertleşmiş Portland çimentosu hamuru içerisindeki bu kimyasal denge, sertleşmiş çimento hamuru içerisine sızan suların ortamın pH değerini düşürmesiyle bozulmaktadır. Sertleşmiş çimento hamuru içerisindeki boşluk sıvısının pH değerinin 12.5 'den daha düşük olması, bazı hidratasyon ürünleri içerisindeki bazı atomların iyon olarak salınımına neden olmaktadır. Yumuşak su içerisindeki karbondioksit, deniz sularındaki sülfat ve klor iyonları, yeraltı suları ve endüstriyel atık sularda bulunan hidrojen iyonları, suyun $\mathrm{pH}$ değerini 6'dan daha düşük bir değere düşürebilmektedir. Bu durum sertleşmiş çimento hamuru için oldukça zararlıdır. Yoğuşma ve sisten meydana gelen ya da buz veya yağmurdan gelen yumuşak sular içerisinde çok az miktarda veya hemen hemen hiç $\mathrm{Ca}^{2+}$ iyonu bulunmaz. Bu tür suların sertleşmiş çimento hamuru ile temas etmesi durumunda, bazı hidratasyon ürünleri içerisindeki $\mathrm{Ca}^{2+}$ iyonları çözünmeye başlar. Sertleşmiş çimento hamuru içerisinden bu tür suların basınçlı bir şekilde akışı durumunda, sertleşmiş çimento hamurunun bozulması çok daha hızlı olmaktadır. Sertleşmiş çimento hamuru içerisindeki $\mathrm{Ca}^{2+}$ iyonunun salınımı, çoğunlukla hidratasyon ürünlerinden birisi olan $\mathrm{CH}^{\prime}$ de meydana gelmektedir. Sertleşmiş çimento hamuru içerisindeki $\mathrm{Ca}^{2+}$ iyonlarının salınımı dayanım azalmasına neden olmaktadır. Örneğin, sertleşmiş çimento hamuru içerisindeki $\mathrm{Ca}^{2+}$ iyonlarının üçte birinin ayrılması, basınç dayanımı değerinin yarıya düşmesine neden olmaktadır. Bu durum, basınçlı saf su etkisine maruz kalan baraj ve akarsu yapılarında büyük problemler ortaya çıkarmaktadır. Baraj yapılarının boşluklu ya da çatlamış betonlarının içerisindeki $\mathrm{CH}^{\prime}$ nin sertleşmiş çimento hamuru içerinden ayrılması çok hızlı olmaktadır. Sertleşmiş çimento hamuru içerisindeki $C H$ 'nin salıverilen miktarı, toplam kireç miktarının \%50'sine kadar ulaşabilmektedir [5].

Betonun bazı özelliklerini iyileştirmede bazı mineral katkılar Portland çimentosuyla birlikte kullanılmaktadır. Puzolanik özelliklere sahip olan silis dumanı (SD) ve uçucu kül (UK), betonda yaygın bir şekilde kullanılan mineral katkılardır. SD ve F sınıfı UK'nin betonun mekanik ve fiziksel özelliklerini iyileştirdiğini bildiren birçok çalışma yapılmıştır. Portland çimentosu klinkerinin ana bileşenleri $C_{3} S, C_{2} S, C_{3} A$ and $C_{4} A F$ 'dir. Bağıntılar çimento kimyasındaki kısaltma harflerle verilmiştir. $\mathrm{Bu}$ ana bileşenlerin hidratasyon ürünleri aşağıda verilmiştir [6].

$2 C_{3} S+11 H=C_{3} S_{2} H_{8}+3 C H$ 


$$
\begin{aligned}
& 2 C_{2} S+9 H=C_{3} S_{2} H_{8}+C H \\
& C_{3} A+3 C \bar{S} H_{2}+26 H=C_{6} A \bar{S}_{3} H_{32} \\
& C_{4} A F+3 C \bar{S} H_{2}+21 H=C_{6}(A F) \bar{S}_{3} H_{32}+(F, A) H_{3}
\end{aligned}
$$

$\mathrm{SD}$ ve $\mathrm{F}$ sınıfı UK'nin, $C_{3} S$ ve $C_{2} S$ ana bileşenlerinin hidratasyonu sonucu meydana gelen $C H$ ve ana bileşenlerden $C_{3} S$ ile reaksiyonları sonucunda aşağı da verilen $C S H$ ürünleri oluşur.

$$
\begin{aligned}
& \mathrm{CH}+\mathrm{S}+\mathrm{H}=\mathrm{CSH} \\
& \mathrm{C}_{3} \mathrm{~S}+2 \mathrm{~S}+10.5 \mathrm{H}=3\left(\mathrm{CSH}_{3.5}\right)
\end{aligned}
$$

Portland çimentosu ve puzolanik reaksiyon sonucunda oluşan $C S H$ ürünleri birbirinin benzeridir. Ancak Portland çimentosunun hidratasyonu sonucu oluşan $C S H$ üründeki $C / S$ oranı, puzolanik reaksiyon sonucunda oluşan $C S H$ 'nin $C / S$ oranından biraz daha büyüktür. Puzolanik reaksiyondan oluşan $C S H$ ürünündeki $\mathrm{C} / \mathrm{S}$ oranı 1 olmasına karşın, $\mathrm{C}_{3} \mathrm{~S}$ ve $\mathrm{C}_{2} \mathrm{~S}$ ana bileşenlerinin hidratasyonu sonucunda meydana gelen $\mathrm{CSH}^{\prime}$ 'nin $\mathrm{C} / \mathrm{S}$ oranı 1.7'dir. C/S oranının azalması, Portland çimentosunun hidratasyonu sonucunda oluşan CSH üzerinde ikincil bir puzolanik reaksiyonun meydana geldiğini gösterir. [6]. SD ve F sınıfı UK'nin puzolanik reaksiyonu sonucunda oluşan CSH ürününden dolayı, boşluk çözeltisinin kompozisyonu değişmektedir. SD ve F sınıfı UK'nin puzolanik reaksiyonundan dolayı, boşluk çözeltisindeki $\mathrm{Ca}^{2+}$ iyonları azalmaktadır. Böylece, Portland çimentosu hamurunun boşluk miktarı da değişmektedir. Boşluk miktarındaki değişimin nedeni şudur; Kullanılan Portland çimentosu miktarı sabit olmasına karşın, SD ve F sınıfı UK kullanıldığından daha fazla CSH üretilir. CSH'in hacmi, SD ve $C H$ 'in toplam hacminden daha büyüktür. Çünkü oluşan $C S H$ ürünü su içermektedir. Dolayısıyla, sertleşmiş hamurdaki boşluk etkili bir şekilde azalmaktadır.

Bu çalışmada, Portland çimentosu yerine, SD ve F sınıfı UK'nin ikili ve üçlü kombinezonlarından oluşan kendiliğinden yerleşen harçların basınçlı su geçirgenliği (BSG) incelenmiştir. SD ve UK mineral katkılarının, betonun BSG üzerine etkileriyle ilgili çalışmalar aşağıda verilmiştir. Ramezanianpour ve ark. [4] kendiliğinden yerleşen 56 günlük betonlardaki BSG derinliğinin, Portland çimentosu ile UK'nin ağırlıkça \%50'ye kadar olan yer değiştirmesinde önemli olmadığını belirtmişlerdir. Ancak \%70'lik bir yer değiştirmede ise, su işleme derinliğinin arttı̆̆ını rapor etmişlerdir. Falaschini ve ark. [7], Portland çimentosu ile UK'nin ağırlıkça \%20 yer değiştirdiği normal betonlarda, su işleme derinliğinin salt Portland çimentosuyla üretilmiş kontrol numunesine kıyasla daha büyük olduğunu ileri sürmüşlerdir. Elrahman ve Hillemeier [8], yüksek performanslı betonlarda, SD ve UK'nin BSG derinliğine etkisini araştırmışlardır. Portland çimentosu ile UK'nin ağırlıkça \%30 yer değiştirmesi durumunda, su işleme derinliğinin kontrol numunesiyle (Portland çimentosu) aynı olduğunu bulmuşlardır. Portland çimentosu ile SD'nin \%10 yer değiştirmesi durumunda ise, BSG değerinin azaldığını ileri sürmüşlerdir. Borosnyoi [9], Portland çimentosu ile SD'nin ağırlıkça \%3, 5, 10 ve 15 yer değiştirmelerinin su geçirgenliğine etkisini incelemiş̧tir. \%5 SD kullanıldığında, su işleme derinliğinin azaldığını ancak \%3, 10 ve 15 yer değiştirme durumlarında arttığını ileri sürmüşlerdir. Ziari ve ark. [10], Portland çimentosu ile SD'nın \% 8 yer değiştirdiği kendiliğinden yerleșen betonlarda su işleme derinliğinin kontrol numunesine kıyasla azaldığını belirtmişlerdir. \%20 UK içeren betonlarda da, su işleme derinliğinin azaldığı belirtilmiştir. Rostami ve Behfarnia [11], alkali aktiviteli granüle cüruf betonlarında, Portland çimentosu ile SD'nin $\% 5,10$ ve 15 yer değiştirmelerini incelemiş ve SD miktarı arttıkça, su işleme derinliğinin kontrol betonuna kıyasla azaldığını iddia etmişlerdir. Görüldüğü gibi, UK ve SD’nin birlikte kullanılmasıyla ilgili olarak, su işleme derinliği üzerine literatürde bir çalışmaya rastlanmamışıır. Ayrıca, mineral katkı olarak UK veya SD kullanılan betonlarda, UK veya SD'nin BSG değerine etkileriyle ilgili olarak literatürdeki sonuçlar birbirinden oldukça farklıdır.

\section{Deneysel Çalışma}

\subsection{Numunelerin hazırlanması}

Bu çalışmada, Türk [12] tarafından hazırlanan numuneler kullanılmış ve bu numunelerin özellikleri Türk [12] tarafindan detaylı bir şekilde verilmiştir. Harç numune karışımlarında, Portland çimentosu (PÇ), F sınıfı UK ve SD kullanılmıştır. Bu malzemelerin kimyasal ve fiziksel özellikleri Tablo 1'de verilmiştir. 
Tablo 1. Malzemelerin kimyasal ve fiziksel özellikleri.

\begin{tabular}{|l|c|c|c|c|c|c|c|c|c|c|}
\hline Bileşenler & $\mathrm{SiO}_{2}$ & $\mathrm{Al}_{2} \mathrm{O}_{3}$ & $\mathrm{Fe}_{2} \mathrm{O}_{3}$ & $\mathrm{CaO}$ & $\mathrm{MgO}$ & $\mathrm{SO}_{3}$ & $\mathrm{Cl}^{-}$ & LOI & Yoğunluk & Özgül yüzey $\left(\mathrm{cm}^{2} / \mathrm{g}\right)$ \\
\hline PC & 20.2 & 5.8 & 3.23 & 64.1 & - & 2.66 & 0.006 & 2.58 & 3.1 & 3484 \\
\hline UK & 58.82 & 19.65 & 10.67 & 2.18 & 3.92 & 0.48 & - & 0.91 & 2.08 & 3812 \\
\hline $\mathrm{SD}$ & 91 & 0.58 & 0.24 & 0.71 & 0.33 & - & - & 1.84 & 2.2 & $96.5 \%<45 \mu \mathrm{m}$ \\
\hline
\end{tabular}

Harç numunelerin karışımında kullanılan malzemelerin miktarları da Tablo 2 ve 3 'te verildi. Kontrol karışımında bağlayıcı olarak sadece PÇ kullanılmıştır. Diğer karışımlarda ise, ikili (PÇ+UK, PÇ+SD) ve üçlü (PÇ+UK+SD) bağlayıcılar kullanılmıştır. Mineral katkı içeren karışımlarda, PÇ miktarı azaltılmış ve azaltılan bu PÇ miktarı yerine mineral katkı kullanılmıştır. Kontrol karışımında $640 \mathrm{~kg} / \mathrm{m}^{3}$ PÇ kullanılmıştır. F sınıfı UK'nın PÇ ile yer değiştirmeleri ağılıkça \%25, 30 ve 35 ve SD'nin \%5, 10, 15 ve 20'dir [12]. Örneğin, SD5UK25 numunesinde, PÇ ile SD ve UK'ün toplam yer değiştirmesi ağırlıkça \%30'dur. Yani, ağırlıkça \%5 SD ve \%25 UK toplamıyla PÇ ağırlığı yer değiştirmiş̧tir. Kendiliğinden yerleşen harç numunelerinin hazırlanması işleminde ASTM C109 [13] standardı takip edilmiş ve taze karışım testleri ise, EFNARC [14]'a göre yapılmıştır. EFNARC [14] 'ta istenilen taze karışım özellikleri, karışımların su/bağlayıcı oranı (W/B) ya da süper akışkanlaştırıcı (SA) miktarları değiştirilerek deneme-yanılma yöntemiyle sağlanmıştır. Karışımlarda dere kumu kullanılmış olup, en büyük tane çap 2 mm'dir. EFNARC [14]'ın belirttiği özellikleri sağlayan taze harç karışımları, 50 mm'lik küp kalıplar içerisine kendiliğinden yerleşmiştir. Numuneler 24 saat sonra kalıplardan çıkarılmış ve 90 gün boyunca su içerisinde kür edilmiştir. Bu süre sonunda, numuneler $105^{\circ} \mathrm{C}$ sıcaklıktaki etüv içerisinde değişmez ağırlığa gelinceye kadar, 24 saat süreyle kurutulmuştur. Hazırlanan bu numuneler üzerinde BSG testi yapılmıştır.

Tablo 2. İkili numunelerdeki malzemelerin karışım miktarları.

\begin{tabular}{|l|l|l|l|l|l|l|l|}
\hline Karışımlar & $\begin{array}{c}\text { W/B } \\
(\%)\end{array}$ & $\begin{array}{c}\text { PC } \\
(\%)\end{array}$ & $\begin{array}{c}\text { UK } \\
(\%)\end{array}$ & $\begin{array}{c}\text { SD } \\
(\%)\end{array}$ & $\begin{array}{c}\text { Binder } \\
\left(\mathrm{kg} / \mathrm{m}^{3}\right)\end{array}$ & $\begin{array}{c}\text { Kum } \\
\left(\mathrm{kg} / \mathrm{m}^{3}\right)\end{array}$ & $\begin{array}{c}\mathrm{SA} \\
\left(\mathrm{kg} / \mathrm{m}^{3}\right)\end{array}$ \\
\hline Kontrol & 0.45 & 100 & 0 & 0 & 640 & 1227 & 6.75 \\
\hline UK25 & 0.43 & 75 & 25 & 0 & 640 & 1194 & 6.75 \\
\hline UK30 & 0.43 & 70 & 30 & 0 & 640 & 1181 & 6.75 \\
\hline UK35 & 0.43 & 65 & 35 & 0 & 640 & 1168 & 6.75 \\
\hline SD5 & 0.44 & 95 & 0 & 5 & 640 & 1230 & 8 \\
\hline SD10 & 0.45 & 90 & 0 & 10 & 640 & 1203 & 8 \\
\hline SD15 & 0.47 & 85 & 0 & 15 & 640 & 1159 & 8 \\
\hline SD20 & 0.50 & 80 & 0 & 20 & 640 & 1106 & 8 \\
\hline
\end{tabular}

Tablo 3. Üçlü numunelerdeki malzemelerin karışım miktarları.

\begin{tabular}{|l|l|l|l|l|l|l|l|}
\hline Karışımlar & $\begin{array}{c}\text { W/B } \\
(\%)\end{array}$ & $\begin{array}{c}\text { PC } \\
(\%)\end{array}$ & $\begin{array}{c}\text { UK } \\
(\%)\end{array}$ & $\begin{array}{c}\text { SD } \\
(\%)\end{array}$ & $\begin{array}{c}\text { Binder } \\
\left(\mathrm{kg} / \mathrm{m}^{3}\right)\end{array}$ & $\begin{array}{c}\text { Kum } \\
\left(\mathrm{kg} / \mathrm{m}^{3}\right)\end{array}$ & $\begin{array}{c}\text { SA } \\
\left(\mathrm{kg} / \mathrm{m}^{3}\right)\end{array}$ \\
\hline SD5UK25 & 0.43 & 70 & 25 & 5 & 640 & 1174 & 8 \\
\hline SD5UK30 & 0.41 & 65 & 30 & 5 & 640 & 1193 & 8 \\
\hline SD5UK35 & 0.41 & 60 & 35 & 5 & 640 & 1185 & 8 \\
\hline SD10UK25 & 0.43 & 65 & 25 & 10 & 640 & 1169 & 8 \\
\hline SD10UK30 & 0.42 & 60 & 30 & 10 & 640 & 1174 & 8 \\
\hline SD10UK35 & 0.41 & 55 & 35 & 10 & 640 & 1166 & 8 \\
\hline SD15UK25 & 0.44 & 60 & 25 & 15 & 640 & 1148 & 8 \\
\hline SD15UK30 & 0.43 & 55 & 30 & 15 & 640 & 1143 & 8 \\
\hline SD15UK35 & 0.43 & 50 & 35 & 15 & 640 & 1140 & 8 \\
\hline SD20UK25 & 0.48 & 55 & 25 & 20 & 640 & 1072 & 8 \\
\hline SD20UK30 & 0.47 & 50 & 30 & 20 & 640 & 1069 & 8 \\
\hline SD20UK35 & 0.47 & 45 & 35 & 20 & 640 & 1061 & 8 \\
\hline
\end{tabular}




\subsection{Basınçlı su geçirgenliği (BSG) testi}

Portland çimentosu yerine ikili ve üçlü sistem mineral katkı kullanılarak elde edilen karışımlardan üretilmiş olan sertleşmiş harç numuneler üzerinde gerçekleştirilen BSG testi, TS EN 12390-8 [15] standardına göre yapılmıştır. TS EN 12390-8 [15] standardında belirtilen 150 mm'lik küp numune ve bu çalışmada kullanılan numune için de uygun olarak tasarlanmış olan BSG düzeneği kullanılmıştır. Bu çalışmada, sertleşmiş harç numuneler kullanıldığından, numunelerin boyutu standartta belirtilen $150 \mathrm{~mm}$ 'den farklı olarak $50 \mathrm{~mm}$ seçilmiştir. Böylece, TS EN 12390-8 [15]'de tarif edilen numune boyutları ve basınçlı suyun temas edeceği yüzey $1 / 3$ oranında küçültülmüştür. 90 günlük deney numuneleri, $105{ }^{\circ} \mathrm{C}$ sıcaklığa sahip etüvde 24 saat kurutulduktan sonra kullanılmıştır.

50 mm'lik küp numunelerde, BSG testi yapmak için, Şekil 1a'de gösterilen mini BSG düzeneği tasarlanmış ve imal edilmiştir. BSG testi düzeneği dört ana kısımdan oluşmuştur. Bu kısımlar; 1-Hava kompresörü, 2-Basınç ayarlayıcı, 3-Su deposu ve Şekil 1b'de gösterilen basınçlı su iletme kafalarıdır. Su iletme kafalarının numune ile temas eden kısımlarında su sızdırmazlığı sağlamak için, lifli lastik contalar kullanılmıştır. Numunenin su ile temas eden yüzey çapı 25 mm'dir.

Basınçlı su 90 dakika süreyle numune üzerine uygulanmıştır. Bu sürenin sonunda, numuneler cihazdan çıkarılmış ve Şekil $2 a$ 'da gösterilen aparat yardımıyla yarılmıştır. Şekil $2 b$ 'de gösterilen yarılmış numunedeki, basınçlı su işleme derinliği $0.5 \mathrm{~mm}$ hassasiyetinde ölçülmüştür.

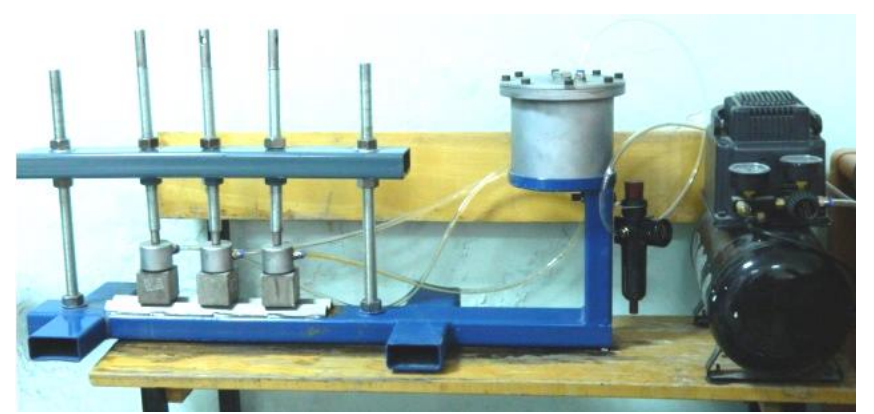

a) BSG test düzeneği.

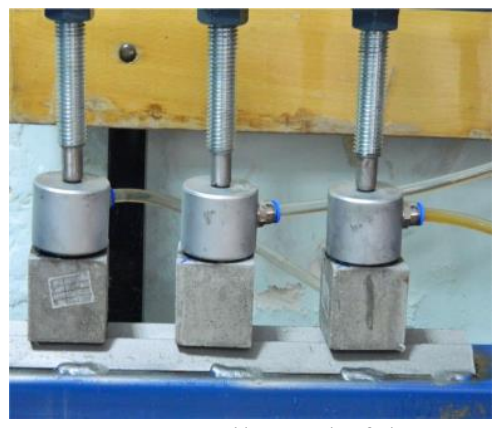

b) Su iletme kafaları.

Şekil 1. BSG test düzeneği.

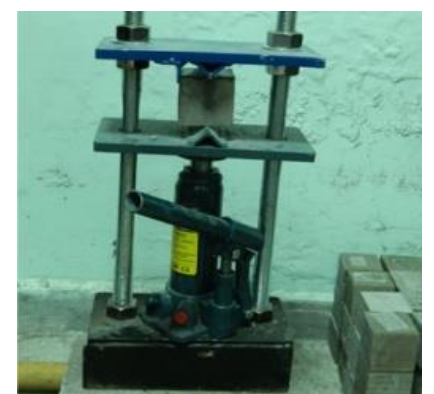

a) Numune yarma aparat1.

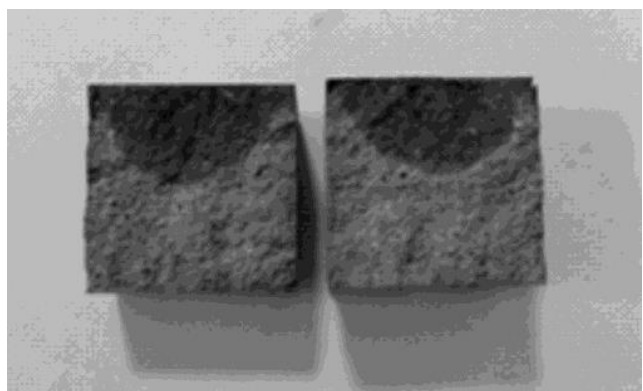

b) Yarılmış numune.

Şekil 2. Yarma aparatı ve numune.

\section{Bulgular ve Tartışmalar}

Şekil 3'te, numunelerin BSG değerleri mm olarak gösterilmiştir. PÇ ve UK içeren numunelerin BSG değerleri, sadece PÇ içeren kontrol numunesinden daha büyük olmuştur. UK25 numunesindeki BSG değeri en büyük olurken, UK30 ve UK35 numunelerinde azalmıştır. Şekil 3'te görüldüğü gibi, UK numuneleri üzerinden bir karşılaştırma yapıldığında, UK miktarı arttıkça BSG değerlerinin doğrusal olarak azalmıştır. Malešev ve ark. [16] tarafından yapılan bir çalışmada da beton içerisinde F sınıfı UK kullanılmıştır. Yapılan bu çalışmada, PÇ ile UK ağırlıkça \%23 yer değiştirdiğinde, kontrol numunesine kıyasla BSG değeri artmış, ancak artan UK 
miktarlarında BSG değerinin azaldığı ileri sürülmüştür. Bu durumun, karışımda kullanılan değişik UK oranlarının, sertleşmiş PÇ hamurunun mikro yapısında değişik etkiler yapmasından kaynaklandığı düşünülmektedir.

SD numunelerinin BSG değerlerinin, farklı PÇ ve SD yer değiştirmelerinde farklılıklar gösterdiği gözlenmiştir. \%5 SD kullanılması durumunda, BSG değeri yaklaşık olarak kontrol numunesine eşit olurken, \%10 SD durumunda en düşük ve kontrol numunesinden de daha az olmuştur. Ancak \%15 ve 20 SD durumlarında BSG değerleri artmıştır. PÇ ile SD’nın ağırlıkça \%10 yer değiştirmesi durumunda, BSG değerinin kontrol numunesine kıyasla azaldığı Elrahman ve Hillemeier [8] tarafından da bulunmuştur. Ziari ve ark. [10], PÇ ile SD'nin \%8 yer değiştirdiği kendiliğinden yerleşen betonlarda BSG değerinin kontrol numunesine kıyasla azaldığını ileri sürmüşlerdir. Borosnyoi [9] tarafından yapılan bir çalışmada ise, PÇ ile SD'nın ağırlıkça \%5 yer değiştirmesi durumunda BSG derinliğinin azaldığını, ancak \%3, 10 ve 15 SD durumunda da arttığını bulmuştur. PÇ ile SD'nın \%5, 10 ve 15 yer değiştirmeleri durumunda, SD miktarı arttıkça BSG değerinin kontrol betonuna kıyasla azaldığı da ileri sürülmüştür [11]. Muhit ve ark. [17], yüksek performanslı betonlarda SD'nin BSG değerine etkisini incelemişılerdir. Çalışmalarında, PÇ ile SD’nin ağırlıkça yer değiştirme miktarlarını \%2.5, 5, 7.5, 10, 15 ve 20 olarak almışlardır. \%10 SD’nin altındaki ve üstündeki miktarların BSG değerini artırdığını, ancak \%10 SD değerinde BSG değerinin etkili bir şekilde azaldığını ileri sürmüşlerdir. Yukarıdaki çalışmalar dikkate alındığında, kullanılan SD miktarlarına bağlı olarak, BSG değerleri de değişmektedir. Fakat bu çalışmada bulunan \%10 SD miktarında BSG değerinin azalması sonucu, literatürdeki çalışmaların büyük çoğunluğu tarafından desteklenmiştir. \%5 SD miktarının PÇ hamurunu $\mathrm{SiO}_{2}$ bakımından doyuramadığı ve böylece mikro yapısını değiştirmede etkisiz kaldığı düșünülmüştür [18]. SD'nin miktarının \%10'dan daha fazla olması durumunda ise, PÇ hamuru içerisinde daha yoğun bir ürün oluştuğu, ancak sertleşmiş hamur içerisindeki mikro boşlukların miktarının artmasına bağlı olarak BSG değerinin de arttığı düşünülmektedir [19].

UK, SD ve PÇ'nin değişik kombinezonlarından oluşan numunelerin BSG değerleri de Şekil 5'te gösterilmiştir. SD5UK25, SD5UK30 ve SD5UK35 numunelerinin BSG değerleri, kontrol numunesi, PÇ-UK ve PÇ-SD karışımı içeren numunelerden daha az olmuştur. UK ve SD'nın birlikte kullanılmasının, UK ve SD'nın tek başlarına kullanılmasıyla kıyaslandığında BSG değerini daha etkili bir şekilde azalttığı görülmüştür.

SD10UK25, SD10UK30 ve SD10UK35 numunelerinin BSG değerleri incelendiğinde, SD10UK35 numunesinin BSG değeri en küçük olmuştur. Bulunan bu sonuç oldukça ilginçtir. Çünkü tekli olarak kullanılan mineral katkılar içerisinde, \%10 SD durumunda BSG değeri en küçük olmuştu. Ayrıca, UK miktarı arttıkça da, PÇ-UK'li numunelerde BSG değerlerinde azalma meydana gelmişti. BSG deneylerinden elde edilen sonuçlar şunu göstermiştir ki, hem PÇ-SD’li numunelerde hem de PÇ-SD-UK içeren numunelerde en uygun SD değeri $\% 10$ olmuştur. SD10UK35 numunesinin BSG değeri, kontrol numunesine kıyasla yaklaşık iki kat daha az olmuştur. Bu durum şöyle izah edilebilir; SD'nin tane büyüklügü̈, UK'nin tane büyüklügünden daha küçüktür. Muhtemelen, sertleşmiş hamur içerisindeki UK tanelerinin arasına SD taneleri etkili bir şekilde yerleşerek boşlukları tıkamış ve böylece BSG değeri azalmıştır.

SD15UK25, SD15UK30 ve SD15UK35 numunelerinin BSG değerleri de, kontrol numunesinden daha küçük olmuş ancak SD10UK35 numunesinden daha büyüktür. SD20UK25 ve SD20UK30 numunelerinin BSG değerleri kontrol numunesinden daha büyük olmasına rağmen, SD20UK35 numunesinin daha az olmuştur. Bu numunelerin de BSG değerleri SD10UK35 numunesinden daha büyük olmuștur.

Shaikh ve Supit [20] tarafından yapılan bir çalışmada, PÇ ile ağırlıkça \%40 F sınıfı UK'nin yer değiștirilerek üretildiği betonlardaki su geçiren boşlukların azaldığı tespit edilmiştir. Şekil 3'te görüldüğü gibi, PÇ-UK numunelerinde ve PÇ-SD-UK numunelerinde, \%25 ve 30 UK değerleriyle kıyaslandığında, \%35 UK durumunda BSG değerinin azaldığı gözlenmiştir. Dolayısıyla, bu çalışmadaki \%35 UK'den elde edilen sonuç ile Shaikh ve Supit [20] tarafından \%40 UK durumu için bulunan sonuçlar benzer olmuştur. 


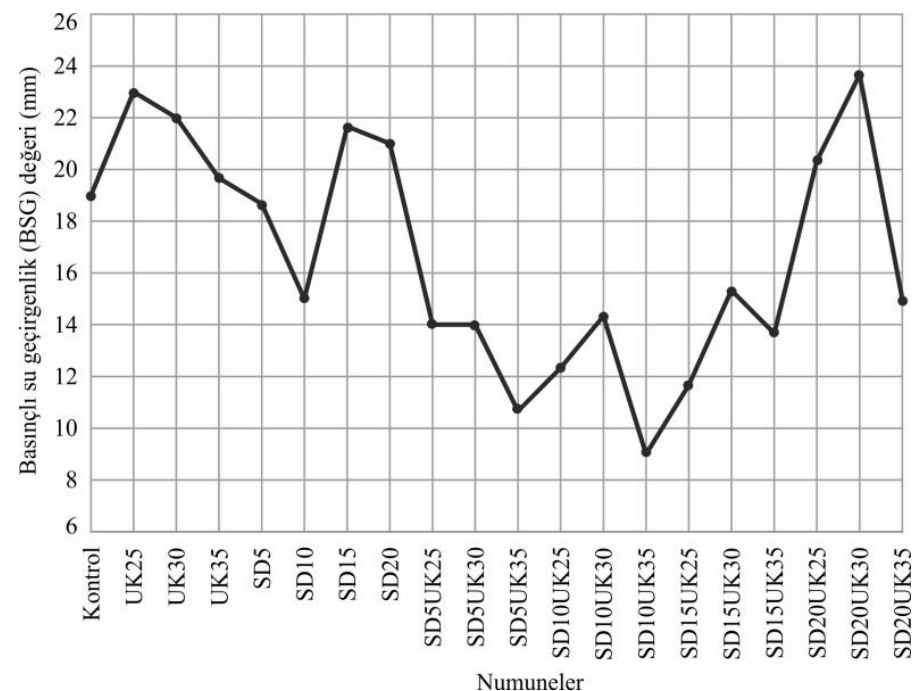

Şekil 3. Kontrol, uçucu kül ve silis dumanlı numunelerin basınçlı su geçirimliliği.

\section{Sonuçlar ve Öneriler}

UK ve SD'li ikili harç karışımlarında, kullanılan UK ve SD miktarlarına göre BSG değerleri değiş̧mektedir. Ağırlıkça \%25, 30 ve 35 UK'nin PÇ ile birlikte kullanılması, kontrol numunesine kıyasla BSG'yi artırmıştır. Ağırlıkça \%25 UK'de BSG değeri en büyük olmuştur. Ağrllıkça \%30 ve 35 UK'deki BSG değerleri, \%25 UK'ye kıyasla azalmışlardır. UK'li numunelerin BSG durumuyla ilgili en önemli sonuç şudur ki, PÇ-UK'li numunelerde \%35'e kadar olan oranlarda UK kullanımı BSG'ni olumsuz yönde etkilemektedir.

PÇ ile SD'nin ağırlıkça \%10 yer değiştirmesi durumunda, BSG değeri etkili bir şekilde azalmıştır. Ancak bu değerin altında ve üstündeki SD oranlarında BSG değerleri artmıştır.

PÇ, UK ve SD üçlü karışımlarında, \%10 SD ve \%35 UK oranlarında, BSG en az olmuştur. Ağırlıkça \%5, 10 ve 15 SD oranları ile $\% 25,30$ ve 35 UK oranları kullanılarak üretilen üçlü karışım numunelerinin BSG değerleri, kontrol numunesine kıyasla azalmış ancak \%20 SD ile \%25 ve \%30 UK oranlarında artmıştır. \%35 UK oranında ise, tekrar azalmıştır.

BSG’nin önemli olduğu yapım uygulamalarında, PÇ ve SD’li ikili karışımlarda ağrılıkça \%10 SD kullanılması önerilmektedir. PÇ, SD ve UK üçlü karışımlarda ise, ağırlıkça \%10 SD ve \%35 UK kullanılması BSG değeri önemli derecede düşürmektedir ve özellikle su yapılarında bu oranların kullanılması önerilmektedir.

SD ve UK'nin değişik oranlarının, BSG davranışında niçin değişkenlikler gösterdiği durumunun bilimsel olarak daha detaylı bir şekilde izah edilebilmesi için, sertleşmiş hamurlar üzerinde mikro yapı incelemelerinin yapılması yararlı olacaktır.

\section{Teșekkür}

Bu çalışma Harran Üniversitesi Bilimsel Araştırmaları Destekleme Birimi (HÜBAK) tarafından, 16197 numaralı proje ile desteklenmiştir. Katkılarından dolayı HÜBAK'na teşekkür ederiz.

\section{Kaynaklar}

[1] Hill RL, Boyd AJ, Dongell JE, Hichborn G, Neal RE, Nmai CK, Leming ML. Guide to durable concrete: Reported by ACI Committee 201, 2008.

[2] Mehta PK and Monteiro PJ. Concrete: Structure, Properties, and Materials. Prentice-Hall, Englewood Cliffs, 1993.

[3] Mehta PK and Gerwick BC. Cracking-corrosion interaction in concrete exposed to marine environment. Concr Int 1982; 4(10): 45-51.

[4] Ramezanianpour AA, Pilvar A, Mahdikhani M, Moodi F. Practical evaluation of relationship between concrete resistivity, water penetration, rapid chloride penetration and compressive strength. Constr Build Mater 2011; 25(5): 2472-2479.

[5] Hewlett P. Lea's chemistry of cement and concrete. Elsevier, 2003.

[6] Mindess S, Young JF, Darwin D. Concrete. Prentice Hall, Upper Saddle River, NJ, 2003. 
[7] Faleschini F, Zanini MA, Brunelli K, Pellegrino C. Valorization of co-combustion fly ash in concrete production. Mater Design 2015; 85: 687-694.

[8] Elrahman MA, Hillemeier B. Combined effect of fine fly ash and packing density on the properties of high performance concrete: An experimental approach. Constr Build Mater 2014; 58: 225-233.

[9] Borosnyói A. Long term durability performance and mechanical properties of high performance concretes with combined use of supplementary cementing materials. Constr Build Mater 2016; 112: 307-324.

[10] Ziari H, Hayati P, Sobhani J. Airfield self-consolidating concrete pavements (ASCCP): Mechanical and durability properties. Constr Build Mater 2014; 72: 174-181.

[11] Rostami M and Behfarnia K. The effect of silica fume on durability of alkali activated slag concrete. Constr Build Mater 2017; 134: 262-268.

[12] Turk K. Viscosity and hardened properties of self-compacting mortars with binary and ternary cementitious blends of fly ash and silica fume. Constr Build Mater 2012; 37: 326-334.

[13] American Society for Testing and Materials. Standard Test Method for Compressive Strength of Hydraulic Cement Mortars. ASTM International, 2013.

[14] EFNARC (2005). The European guidelines for self-compacting concrete: Specification, production and use.

[15] TS EN 12390-8 Beton - sertleşmiş beton deneyleri - bölüm 8: basınç altında su işleme derinliğinin tayini. Türk Standartları Enstitüsü, Ankara, 2010.

[16] Malešev, M, Malešev M, Radonjanin V, Draganić S, Šupić S, Laban M. Influence of fly ash and decreasing waterpowder ratio on performance of recycled aggregate concrete. Gradevinar 2017; 69(09): 811-820.

[17] Muhit IB, Ahmed SS, Amin MM, Raihan MT. Effects of Silica fume and Fly ash as partial replacement of cement on water permeability and strength of high performance concrete. In 4th International Conference on Advances in Civil Engineering;2013; AETACE, Association of Civil and Environmental Engineers. 108-115.

[18] Mitchell DRG, Hinczak I, Day RA. Interaction of silica fume with calcium hydroxide solutions and hydrated cement pastes. Cem Concr Res 1998; 28(11): 1571-1584.

[19] Monteny J, De Belie N, Taerwe L. Resistance of different types of concrete mixtures to sulfuric acid. Mater Struct 2003; 36(4): 242-249.

[20] Shaikh FU, Supit, SW. Compressive strength and durability properties of high volume fly ash (HVFA) concretes containing ultrafine fly ash (UFFA). Constr Build Mater 2015; 82: 192-205. 